\title{
The utility of delivery ward register data for determining the causes of perinatal mortality in one specialized and one general hospital in south Ethiopia
}

Tesfalidet Beyene ${ }^{1,2^{*}}$, Catherine Chojenta ${ }^{3}$, Roger Smith ${ }^{4}$ and Deborah Loxton ${ }^{3}$

\begin{abstract}
Background: Globally, the burden of perinatal mortality is high. Reliable measures of perinatal mortality are necessary for planning and assessing prenatal, obstetric, and newborn care services. However, accurate record-keeping is often a major challenge in low resource settings. In this study we aimed to assess the utility of delivery ward register data, captured at birth by healthcare providers, to determine causes of perinatal mortality in one specialized and one general hospital in south Ethiopia.

Methods: Three years (2014-2016) of delivery register for 13,236 births were reviewed from July 12 to September 29, 2018, in two selected hospitals in south Ethiopia. Data were collected using a structured pretested data extraction form. Descriptive statistics assessed early neonatal mortality rate, stillbirth rate, perinatal mortality rate and causes of neonatal deaths. Factors associated with early neonatal deaths and stillbirths were examined using logistic regression. The adjusted odds ratios with a 95\% confidence interval were reported to show the strength of the association.

Result: The perinatal mortality ratio declined from 96.6 to 75.5 per 1000 births during the three-year study period. Early neonatal mortality and stillbirth rates were 29.3 per 1000 live births and 55.2 per 1000 total births, respectively. The leading causes of neonatal death were prematurity $47.5 \%$, and asphyxia $20.7 \%$. The cause of death for $15.6 \%$ of newborns was not recorded in the delivery registers. Similarly, the cause of neonatal morbidity was not recorded in $1.5 \%$ of the delivery registers. Treatment given for $94.5 \%$ of neonates were blank in the delivery registers, so it is unknown if the neonates received treatment or not. Factors associated with increased early neonatal deaths were maternal deaths and complications, vaginal births, APGAR scores less than 7 at five minutes and low birth weight (2500 g). Maternal deaths and complications and vaginal births were associated with increased stillbirths.
\end{abstract}

Conclusion: Our findings show that an opportunity exists to identify perinatal death and newborn outcomes from the delivery ward registers, but some important neonatal outcomes were not recorded/missing. Efforts towards improving the medical record systems are needed. Furthermore, there is a need to improve maternal health during pregnancy and birth, especially neonatal care for those neonates who experienced low APGAR scores and birth weight to reduce the prevalence of perinatal deaths.

\footnotetext{
*Correspondence: ttesfalove@gmail.com; Tesfalidet.Beyene@newcastle.edu.

au

${ }^{2}$ Hunter Medical Research Institute, Lot 1 Kookaburra Circuit, New

Lambton Heights, NSW 2305, Australia

Full list of author information is available at the end of the article
}

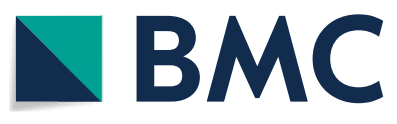

(c) The Author(s) 2021. Open Access This article is licensed under a Creative Commons Attribution 4.0 International License, which permits use, sharing, adaptation, distribution and reproduction in any medium or format, as long as you give appropriate credit to the original author(s) and the source, provide a link to the Creative Commons licence, and indicate if changes were made. The images or other third party material in this article are included in the article's Creative Commons licence, unless indicated otherwise in a credit line to the material. If material is not included in the article's Creative Commons licence and your intended use is not permitted by statutory regulation or exceeds the permitted use, you will need to obtain permission directly from the copyright holder. To view a copy of this licence, visit http://creativecommons.org/licenses/by/4.0/. The Creative Commons Public Domain Dedication waiver (http://creativeco mmons.org/publicdomain/zero/1.0/) applies to the data made available in this article, unless otherwise stated in a credit line to the data. 
Keywords: Perinatal deaths, Birth, Utility, Delivery ward register, Ethiopia

\section{Background}

Globally, the burden of perinatal mortality is high and intrapartum complications are important contributors to perinatal deaths especially in low-income countries [1-3]. Perinatal mortality is an important indicator of the quality of antenatal, intrapartum, and newborn care $[4,5]$. Perinatal mortality refers to the number of stillbirths and deaths in the first week of life (early neonatal mortality). For every baby who dies in the first week after birth, another is born dead (stillbirths) [4]. For international comparison, the World Health Organization (WHO) defines stillbirth as a baby born with no signs of life at or after 28 weeks gestation [6]. Worldwide, 2.6 million stillbirths and 2.6 million neonatal deaths occur each year. Most of these deaths occur in low-middle income countries [7-9]. Sub-Saharan Africa and South Asia account for three-quarters of stillbirths. About 1.3 million (half) of all stillbirths occur during labour and birth [7]. Newborns face the highest risk of dying in their first four weeks of life, at an average global rate of 18 deaths per 1000 live births [9].

Perinatal death is associated with poor maternal health care, inadequate care during pregnancy and childbirth, inappropriate management of complications, poor hygiene during the first critical hours after birth and poor newborn care $[4,7,10]$. It has been reported that preterm birth, intrapartum complications (birth asphyxia), infection, and hypertensive disease are the most common contributors to perinatal death in low- and middle-income countries (LMIC) [9, 11-13]. Most perinatal deaths are preventable with the provision of high-quality care and timely interventions, especially during labour and delivery [13].

Globally there is a scarcity of quality information on the causes of perinatal death [14]. Reliable measures of perinatal mortality are necessary for planning and assessing prenatal, obstetric, and newborn care services. Accurate record-keeping is often a major challenge in low resource settings $[5,15]$. Thus, the true burden of perinatal death is unclear. The WHO recommends collecting data on intrapartum care and neonatal mortality rates (NMR) as part of emergency obstetric care indicators. This will allow health care providers to take the most appropriate measures to prevent maternal and perinatal deaths [16]. However, in most countries, particularly where the estimated burden of perinatal death is highest, most stillbirths and half of all newborn deaths are not registered [14].
Ethiopia has achieved remarkable declines in underfive mortality rates $[17,18]$. However, neonatal mortality rates remain unacceptably high [19]. A 2020 meta-analysis of perinatal mortality has shown that perinatal mortality in Ethiopia was 51.3 per 1000 total births (95\% CI: 40.8-62.8) [20], and stillbirth and early neonatal mortality rates were 36.9 per 1000 births (95\% CI: $27.3-47.8)$ and 29.5 per 1000 live births (95\% CI: 23.9-35.6), respectively. This study has highlighted that the reduction trend of overall perinatal mortality was slow in the country.

Accurate recording and reporting of the number of stillbirths and neonatal deaths provide the data needed to improve and target health system responses and to measure outcomes in relation to policy and practice initiatives. Thus, we aimed to assess the utility of delivery ward register data, captured at birth by healthcare providers, to determine the causes of perinatal mortality in one specialized and one general hospital in south Ethiopia.

\section{Methods \\ Study area}

We collected secondary data from Hawassa University Comprehensive Specialized Hospital (HUCSH) and Durame General Hospital (DGH), Southern Nations, Nationalities and Peoples' Region (SNNPR). The SNNPR is located in the south part of Ethiopia. The capital city (Hawassa) is located $285 \mathrm{~km}$ from Addis Ababa. The region has a total population of 15 million people, of whom $50 \%$ are women [21]. The 2014 Regional Health Bureau reported that the region has 21 public hospitals [22].

HUCSH is a referral teaching hospital, and top level ranked in the three-tier Ethiopian health care system. It delivers services for more than 18 million people. It has over 400 beds for inpatient services including three operating rooms for obstetric and gynaecological surgeries. Over 4000 births per year occur within the hospital, of which 30 to $35 \%$ are caesarean section. The DGH is located in Durame City and serves as a referral hospital for the Kembata Tembaro zone. The hospital provides services to over 1 million people and oversees 1700 deliveries annually. At the time of this study, each hospital has a neonatal intensive care unit that provides speciality care for newborns. However, the teaching hospital (HUCSH) is well equipped and has a higher number of paediatricians/neonatologists than the regional hospital. 


\section{Study design and period}

A hospital-based retrospective study was conducted to assess the utility of the delivery register data to determine the causes of perinatal death in both hospitals over three years (2014-2016). The study was carried out from 12 July to 29 September 2018.

\section{Study population}

The delivery ward register of all deliveries between 2014-2016.

Documentation in delivery ward registers is routinely undertaken by facility health care providers and used to follow ward admissions and discharges after birth. Maternal age, mode of delivery, maternal wellbeing, newborn sex, birth outcomes, care and interventions for newborns are documented in this register.

\section{Inclusion and Exclusion criteria}

Inclusion Delivery registries, which have recorded details of birth and deaths of the newborns.

Exclusion criteria Delivery before 28 weeks of gestation (abortion) had been excluded since they were not stillbirths or early neonatal death.

\section{Source of data and Data collection procedure}

Data was collected using a structured pretested data extraction form. The extraction form was developed by examining the registration books of participating facilities. A template was prepared using an online survey tool (Survey Gizmo) and downloaded on iPads for offline data collection. Two data collectors and supervisors who had experience in data extraction were recruited to collect data. Delivery ward register data were reviewed, and the mothers' cards were identified by medical registration/ card number. Two data assistants were recruited to identify newborn charts. Data collected from delivery ward registers include maternal age, mode of delivery, APGAR score, birth weight, whether death occurred before or after arrival at the health facility, breastfeeding status, treatment given, treatment outcomes, and maternal complications. The principal investigator and supervisors oversaw the data collection process by checking the information collected and providing feedback.

\section{Quality assurance}

Before actual data extraction, a pre-test was conducted to assess whether appropriate variables were included in the data extraction form. All required amendments to the tool were completed based on the pre-test. In addition to the pre-test, data collectors and supervisors were recruited based on prior experience in data extraction techniques. Two days of training was undertaken by data collectors and supervisors. Training focused on the study rationale, use of Ipads, Survey Gizmo, handling of data and the techniques for filling in the data extraction form.

\section{Data processing and analysis}

Data were exported from Survey Gizmo into SPSS software (version 20) for analysis. Descriptive statistics were used to show early neonatal mortality rates (ENMR), stillbirth rates and perinatal mortality rates (PNMR). The PNMR was calculated by dividing the total number of neonatal deaths and stillbirths for the three-year period with the total amount of births within the same period and then converted to 1000 total births. The overall level of ENMR was calculated by dividing the total number of newborn deaths for the three-year period with the total number of live births within the same period and then translated into 1000 live births. The stillbirth rate was calculated by dividing the total number of stillbirths for the three-year period with the total number of births and then translated to 1000 total births. Trends in overall neonatal and perinatal mortality, as well as stillbirth rates during the period were examined using a simple linear regression model.

The univariable logistic regression model was used to obtain unadjusted associations between early neonatal deaths and stillbirth, and maternal and neonatal characteristics. All variables having $\mathrm{p}$-values $<0.2$ were entered into a multivariable logistic regression model to control for possible confounding factors. Strength of association was expressed as adjusted odds ratio (AOR) with 95\% confidence intervals (CI). The goodness of fit of the models was examined using the Hosmer-Lemeshow $x^{2}$ test with 10 subgroups, where $\mathrm{p}>0.05$ indicated a satisfactory model. Furthermore, variance inflation factor (VIF) was used to check multicollinearity among independent variables. However, the dichotomous measure of maternal complications (Yes/No) had multicollinearity with types of maternal complications, so we dropped types of complications from the multivariable models. Twin pregnancies were excluded from the analysis as they have high odds of death and may distort the effect size.

\section{Results}

A total of 13,236 birth were included in this study. Of the total delivery register, $45 \%$ of records were from the year 2016. The majority of data $(64.8 \%)$ were collected from Hawassa University comprehensive specialized hospital. Over one third (37.6\%) of women were in the age category 21-25 years. Most (64.8\%) women gave birth vaginally. Sixty-eight mothers died in hospitals and $15.7 \%$ of mothers developed complications. Pre-eclampsia or 
eclampsia was the leading (31.0\%) maternal complication. Maternal complications in $16.0 \%$ of mothers were not specified/recorded in the delivery register. Four hundred and thirteen (3.1\%) mothers had a history of previous caesarean sections. The majority (91.4\%) of births were singleton (Table 1 ).

\section{Characteristics of neonates}

More than half $(53.7 \%)$ of neonates were male. Nine percent of neonates had APGAR scores of less than seven at five minutes. Of the total neonates, $1622(12.6 \%)$ were low birth weight $(<2500 \mathrm{~g})$. One in nine $(11.0 \%)$ neonates developed morbidity. The majority $(79.8 \%)$ of the morbidities were related to prematurity, followed by perinatal asphyxia (12.2\%). However, the cause of the newborn morbidity was not recorded for $22(1.5 \%)$ newborns in the delivery register. Three hundred and seventy-seven (2.9\%) neonates died. Many of the neonates died at the hospitals (93.9\%). Breastfeeding was initiated within one hour in $94.6 \%$ of neonates. However, mode of feeding was not recorded for $41(0.3 \%)$ newborns. Treatment given in $94.5 \%$ of neonates were blank in the delivery register, so it is unknown if neonates received treatment or not (Table 2).

\section{Cause of early neonatal death}

The leading causes of neonatal death were prematurity $179(47.5 \%)$, followed by asphyxia $78(20.7 \%)$. The cause of death for 59 (15.6\%) newborns were not recorded in the delivery register (Fig. 1).

\section{Perinatal death}

A total of 1129 perinatal deaths were identified during the study period. The PNMR in the study was 82.9 per 1000 total births $(95 \%$ CI 78.3, 87.5). Two thirds (66.6\%) were stillbirths and $33.4 \%$ were neonatal deaths (Fig. 2).

The number of perinatal deaths (early neonatal death and stillbirth) per year and the corresponding PMRs with 95\% confidence intervals are presented in Table 3. The overall PMR was 82.9 (95\%CI; 78.3-87.6). The overall stillbirth and early neonatal mortality rates were 55.2 (95\%CI; 51.4-59.2) per 1000 total births and 29.3 (95\%CI; 26.4-32.4) per 1000 live births, respectively.

\section{Trends of perinatal deaths}

Across the study period, the trend of the ENMR varied with the highest observed in 2014 with 51.4 per 1000 live births and the lowest observed in 2016 with 21.9 per 1000 live births. There was a slow declining trend in ENMR during the reference period in the study area with a gradient of 14.5 on a linear scale (Fig. 3).

Across study years, the trend of stillbirths varied, with the highest being observed in 2015 with 57.5 per 1000 births and the lowest observed in 2014 with 47.7 per 1000 births. There was an increasing trend in stillbirths during the reference period in the study area, with a gradient of 3.5 on a linear scale (Fig. 4).

Across the study period the trend of the PMRs varied, with the highest being observed in 2014 with 96.6 per 1000 births and the lowest observed in 2016 with 75.5 per 1000 births. There was a reduction in trend in PMRs during the reference period in the study area, with a gradient of 10.5 on a linear scale (Fig. 5).

\section{Maternal complications in perinatal deaths (early neonatal deaths and stillbirths)}

The leading cause of early neonatal deaths relating to maternal complications was pre-eclampsia or eclampsia (33.8\%) followed by haemorrhage (17.0\%). However, the cause of early neonatal deaths in $13.6 \%$ of births related to maternal complications was not recorded in the delivery register. The leading cause of stillbirths due to maternal complications was haemorrhage (28.4\%) followed by pre-eclampsia/eclampsia (25.1\%). However, the cause of stillbirths in $11.3 \%$ of delivery's related to maternal complications was not recorded in the delivery register (Fig. 6).

\section{Determinants of early neonatal mortality}

Regarding univariable analysis, age of the mother, mode of delivery, maternal death and complications, history of caesarean section, sex of the newborn, APGAR score less than 7 at five minutes and low birth weight $(<2500 \mathrm{~g})$ were associated with early neonatal deaths. In multivariable analysis, neonates born to mothers who died/unstable (AOR 7.54; 95\% CI 4.14-13.71) and mothers who had complications (AOR 2.71; 95\% CI 2.01-3.66) had higher odds of death than neonates born to mothers who survived and didn't experience complications. Vaginal birth was found to increase the likelihood of early neonatal deaths compared to caesarean section (AOR 3.08; 95\% CI 2.23-4.25). Neonates who had an APGAR score of less than 7 at five minutes (AOR 4.40; 95\% CI 3.28-5.91) were found to have an increased likelihood of neonatal death than neonates who had APGAR sore 7 or more at five minutes. Neonates who had low birth weight $(<$ $2500 \mathrm{~g}$ ) (AOR 6.4; 95\% CI 4.77-8.58) had a higher odds of death than neonates who had birth weight $2500 \mathrm{~g}$ or more (Table 4).

\section{Determinants of stillbirths}

Univariable age of the mothers, mode of delivery, maternal deaths and complications were associated with increased stillbirths. In multivariable analysis, the odds of having stillbirths was two times higher (AOR 2.47; 95\% CI 2.06-2.96) among mothers who had vaginal births 
Table 1 Pregnancy outcomes and maternal characteristics in one specialized and one general hospital in south Ethiopia, 2014-2016

Variables

Number (\%)

Year, $\mathrm{n}=13,236$

2014

$1564(11.8)$

2015

$5633(42.6)$

2016

$6039(45.6)$

Name of the Hospital, $n=13,236$

Durame Hospital

4655 (35.2)

Hawassa Referral Hospital

$8581(64.8)$

Age category, $n=13,236$

$<=20$

$2139(16.2)$

$21-25$

$4983(37.6)$

26-30

$4432(33.5)$

31-35

$1315(9.9)$

$>35$

$367(2.8)$

Mode of delivery, $n=13,236$

Spontaneous Vaginal delivery

$7142(54)$

Caesarean section

$4670(35.2)$

Episiotomy

$105(0.8)$

Forceps or vacuum extraction

1319 [10]

Maternal status, $n=13,236$

Died

$68(0.5)$

Stable

$13,084(98.9)$

Unstable or deteriorated or referred to the next health facility

$84(0.6)$

Maternal complication, $n=13,236$

Yes

No

Type of complication ${ }^{\mathrm{a}}, \mathbf{n}=\mathbf{2 0 8 1}$

Pre-eclampsia /Eclampsia

Antepartum haemorrhage

$271(13.0)$

Postpartum Haemorrhage

164 (7.9)

Sepsis

$36(1.7)$

Obstructed labor/Prolonged labor

459 (22.0.)

Uterine rupture

$83(4.0$.)

Premature Rupture of the Membrane

$89(4.3)$

Cephalopelvic disproportion

$36(1.7)$

Complication referred

$33(1.6)$

Other*

$82(3.9)$

Not recorded or missing

$334(16.0)$

Previous history of caesarean section, $n=13,236$

Yes

$413(3.1)$

No

Pregnancy outcome, $n=13,236$

Single

$12,096(91.4)$

Twin

Stillbirths

739 (5.6)

Macerated

$13(0.1)$

Other* $^{*}$ Anaemia, Diabetic Mellitus, HIV, malaria, Hepatitis, Pneumonia, Pulmonary edema, bad obstetric history, cardiac disease, ${ }^{a}$ more than one answer 
Table 2 Neonatal characteristics of neonates delivered in one specialized and one general hospital in south Ethiopia, 20142016

\begin{tabular}{|c|c|}
\hline Variables & Number (\%) \\
\hline \multicolumn{2}{|l|}{ Sex for live births, $n=12,872$} \\
\hline Female & $5957(46.3)$ \\
\hline Male & $6915(53.7)$ \\
\hline \multicolumn{2}{|l|}{ APGAR Score at fifth minutes, $n=12,872$} \\
\hline$<7$ & $1139(8.8)$ \\
\hline$>=7$ & $11,733(91.2)$ \\
\hline \multicolumn{2}{|l|}{ Birth weight (gm), $n=12,872$} \\
\hline$<2500$ & $1622(12.6)$ \\
\hline$>=2500$ & $11,250(87.4)$ \\
\hline \multicolumn{2}{|l|}{ The Newborn developed morbidity, $n=12,872$} \\
\hline Yes & $1420(11.0)$ \\
\hline No & $11,452(89)$ \\
\hline \multicolumn{2}{|l|}{ Newborn morbidity ${ }^{a}, n=1420$} \\
\hline Prematurity & $1134(79.8)$ \\
\hline Perinatal Asphyxia & $173(12.1)$ \\
\hline Sepsis & $63(4.4)$ \\
\hline Congenital malformation & $21(1.5)$ \\
\hline Meconium Aspiration & $8(0.6)$ \\
\hline HIV & $24(1.7)$ \\
\hline Other & 43(3.0.) \\
\hline Not recorded or missing & $22(1.5)$ \\
\hline \multicolumn{2}{|l|}{ Newborn outcome, $n=12,872$} \\
\hline Died & $377(2.9)$ \\
\hline Not died & $12,495(97.1)$ \\
\hline \multicolumn{2}{|l|}{ Survived newborn $n=12,495$} \\
\hline Home and improved & $12,185(97.5)$ \\
\hline Referred & $310(2.5)$ \\
\hline \multicolumn{2}{|l|}{ Newborn died $n=377$} \\
\hline Live birth died after arrival or delivery in facility & $354(93.9)$ \\
\hline Live birth died before arrival at facility & $23(6.1)$ \\
\hline \multicolumn{2}{|l|}{ Mode of feeding, $n=12,872$} \\
\hline Breast feeding initiated after one hour & $383(3.0)$ \\
\hline Breastfeeding initiated within one hour & $12,182(94.6)$ \\
\hline Other feeding not recorded & $266(2.1)$ \\
\hline Not recorded & $41(0.3)$ \\
\hline \multicolumn{2}{|l|}{ Treatment given ${ }^{a}, n=12,872$} \\
\hline Oxygen/Resuscitation & $488(3.8)$ \\
\hline Kangaroo Mother Care & $153(1.2)$ \\
\hline Antibiotics & $83(0.6)$ \\
\hline Blood transfusion & $13(0.1)$ \\
\hline Other & $101(0.8)$ \\
\hline Not recorded & $12,166(94.5)$ \\
\hline
\end{tabular}

a more than one \# the $\mathrm{n}$ includes live twin births

compared to caesarean births. Mothers who died/unstable (AOR 2.51; 95\% CI 1.74-3.62) and experienced complications (AOR 8.59; 95\% CI 7.26-10.17) had a higher odd of having stillbirths compared to mothers who survived and didn't have complications (Table 5).

\section{Discussion}

To our knowledge, this study is the first of its kind to be undertaken in Ethiopia that utilizes delivery ward register data to identify perinatal deaths and assess gaps in documentation/recording of newborn outcomes. The findings of our study show that perinatal deaths declined over the three-year period in the study area. Our findings also show that an opportunity exists to identify perinatal death and newborn outcomes from the delivery registers, but some important neonatal outcomes were either not recorded or not recorded reliably.

We found that maternal deaths and complications, vaginal births, newborn APGAR score less than 7 at five minutes and newborn birth weight $(<2500 \mathrm{~g})$ were associated with increased early neonatal deaths. Our findings also show that vaginal births, maternal deaths and complications were associated with an increased likelihood of stillbirths.

The findings of this study identified several limitations in the maintenance of records in both hospitals. One of our findings revealed a lack of a universal system for recording births and care provided to newborns in both hospitals. The cause of neonatal death was not recorded in nearly one-sixth of the delivery register. Similarly, the cause for neonatal morbidity was not recorded in $1.5 \%$ of the delivery register. A study undertaken in Tanzania found that $33.3 \%$ of all newborn deaths were properly documented but the cause of death was only reported in $38 \%$ of cases [23]. A study in Bangladesh revealed that the quality of neonate medical records by cause of death was lower when compared with adult records [24]. This suggests a gap in low resource settings in recording the cause of newborn deaths and that information provided within such records was often inadequate. A meta-analysis on perinatal death reviews done in low and middle-income countries revealed reviewing deaths may reduce perinatal death by $30 \%$ and improve quality of care [25]. The findings of the present study imply there is a gap in records of the delivery register that needs to be improved to identify causes of newborn deaths.

In our study, $94.5 \%$ of treatments neonates received were not recorded in the delivery register indicating poor documentation and a missed opportunity for identifying the efficacy of treatment outcomes. It has been reported that poor documentation of medical records leads to suboptimal care [26]. A study in Malawi demonstrated the importance of record-keeping in assessing critically ill neonates and determining factors that were contributing to newborn deaths [27]. Taken together, these studies suggest that poor documentation may result in 


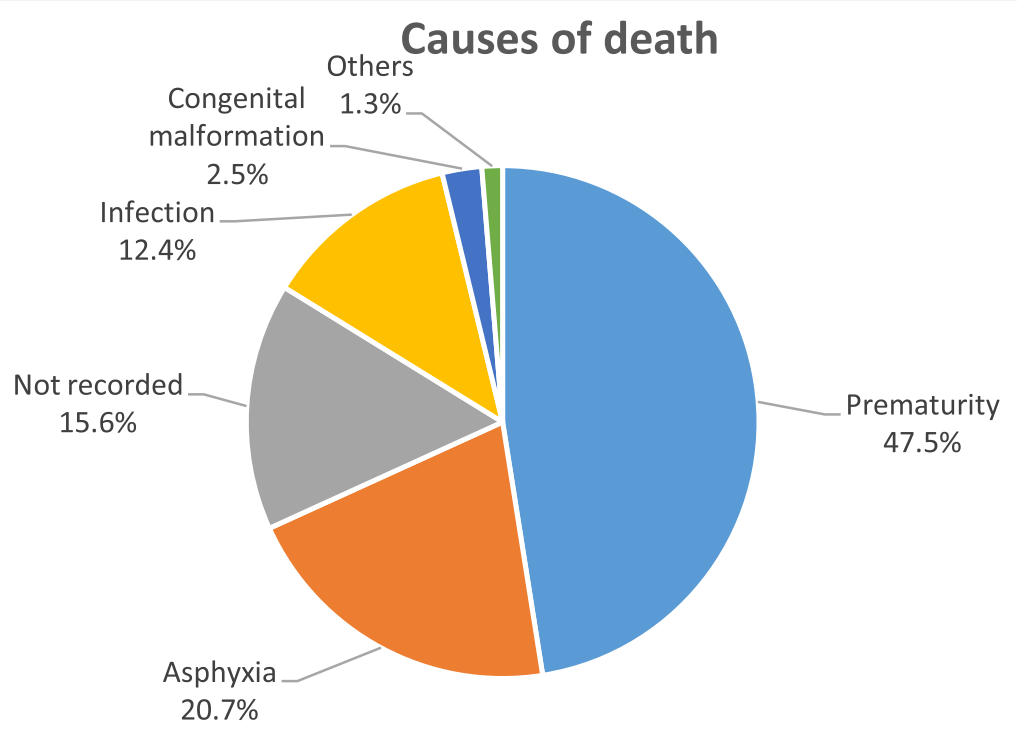

Fig. 1 Cause of early neonatal deaths in one specialized and one general hospital in south Ethiopia, 2014-2016

\section{Perinatal mortality}

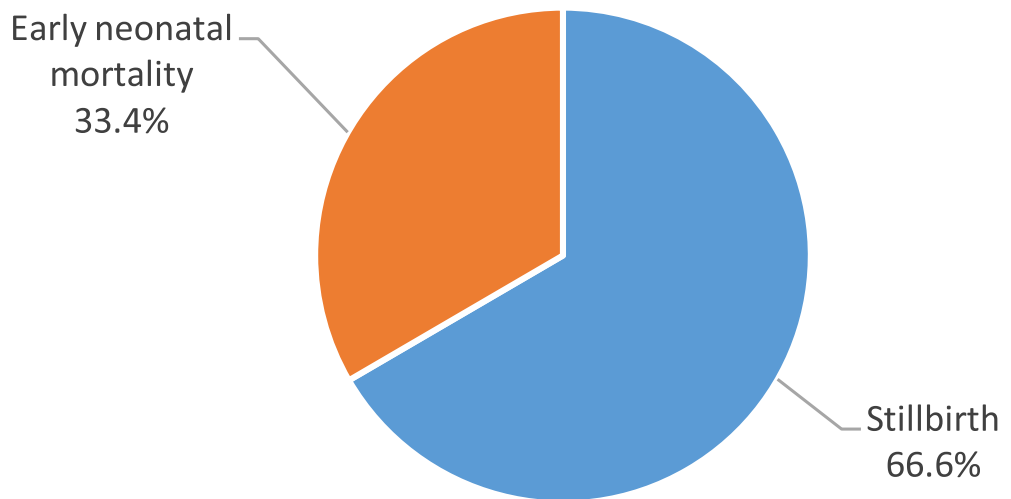

Fig. 2 Percentage of neonatal deaths and stillbirths in one specialized and one general hospital in south Ethiopia, 2014-2016

Table 3 Annual perinatal mortality ratios over the three years period (2014-2016) in one specialized and one general hospital in south Ethiopia

\begin{tabular}{llllllll}
\hline Year & $\begin{array}{l}\text { Number of } \\
\text { deliveries }\end{array}$ & $\begin{array}{l}\text { Number of } \\
\text { live births }\end{array}$ & $\begin{array}{l}\text { Number of } \\
\text { stillbirths }\end{array}$ & $\begin{array}{l}\text { Stillbirths per 1000 } \\
\text { deliveries with 95\%Cl }\end{array}$ & $\begin{array}{l}\text { Number of early } \\
\text { neonatal deaths }\end{array}$ & $\begin{array}{l}\text { NMR per 1000 live } \\
\text { births with 95\%Cl }\end{array}$ & PNMR with 95\%Cl \\
\hline 2014 & 1615 & 1538 & 77 & $47.7(37.3-58.1)$ & 79 & $51.4(40-62.4)$ & $96.6(82.2-110.1)$ \\
2015 & 5787 & 5454 & 333 & $57.5(51.5-63.5)$ & 169 & $30.9(26.3-35.5)$ & $86.7(79.5-93.9)$ \\
2016 & 6222 & 5880 & 342 & $55(49.3-60.7)$ & 129 & $21.9(18.2-25.6)$ & $75.5(69.1-82.3)$ \\
Total & 13,624 & 12,872 & 752 & $55.2(51.4-59.2)$ & 377 & $29.3(26.4-32.4)$ & $82.9(78.3-87.6)$ \\
\hline
\end{tabular}

\# the $\mathrm{n}$ includes live twin births 


\section{Early Neonatal Mortality per 1000 live births}

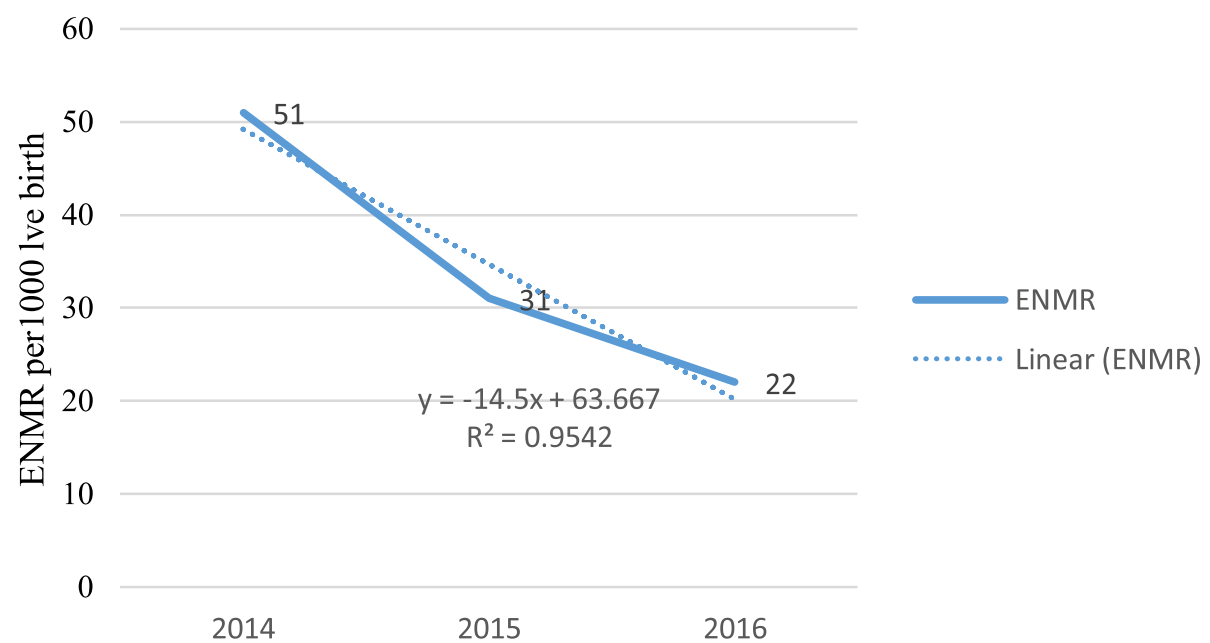

Fig. 3 Trends in early neonatal mortality rate in one specialized and one general hospital in south Ethiopia, 2014-2016. $R^{2}$ refers to a measure of the reliability of the relation between the years and early neonatal deaths

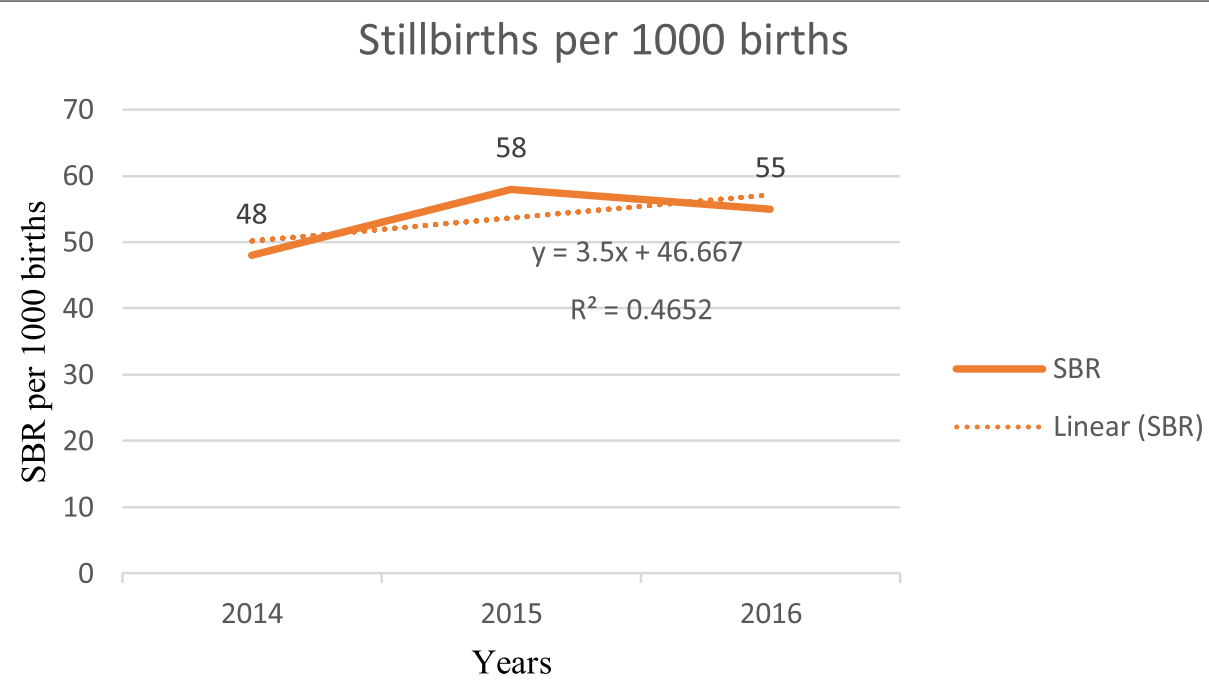

Fig. 4 Trends in stillbirth rates in one specialized and one general hospital in south Ethiopia, 2014-2016. R² refers to a measure of the reliability of the relation between the years and early stillbirths

suboptimal care and hinder treatments to reduce newborn deaths.

Studies have indicated that most perinatal deaths occur due to maternal complications [2, 28]. In the current study, preeclampsia or eclampsia and haemorrhage were the leading causes of early neonatal deaths and stillbirths, respectively. However, $13.6 \%$ of causes of early neonatal deaths and $11.3 \%$ of stillbirths related to maternal complications were not recorded in the delivery register. Maternal complications were often missing from the delivery register. These data indicate a need for improvement of documentation in delivery registers to facilitate preventive measures relating to maternal complications and perinatal deaths.

Our findings indicate that the trend of newborn mortality varied over the three years. Newborn mortality reduced from 51 to 22 per 1000 live births. While the reduction in child mortality rates in Ethiopia are encouraging $[19,29]$ this reduction is likely to be unchanged if the quality of documentation in delivery 


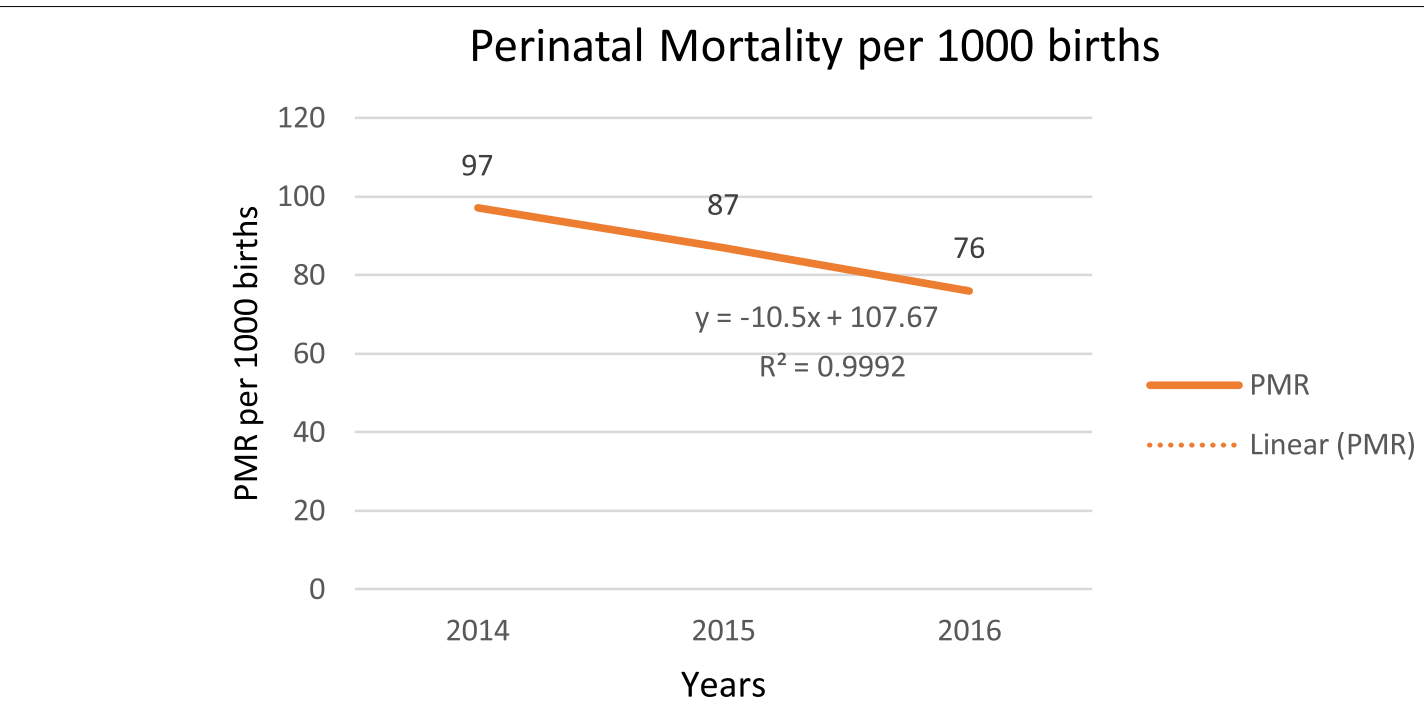

Fig. 5 Trends in perinatal mortality ratio in one specialized and one general hospital in south Ethiopia, 2014-2016. $R^{2}$ refers to a measure of the reliability of the relation between the years and perinatal mortality

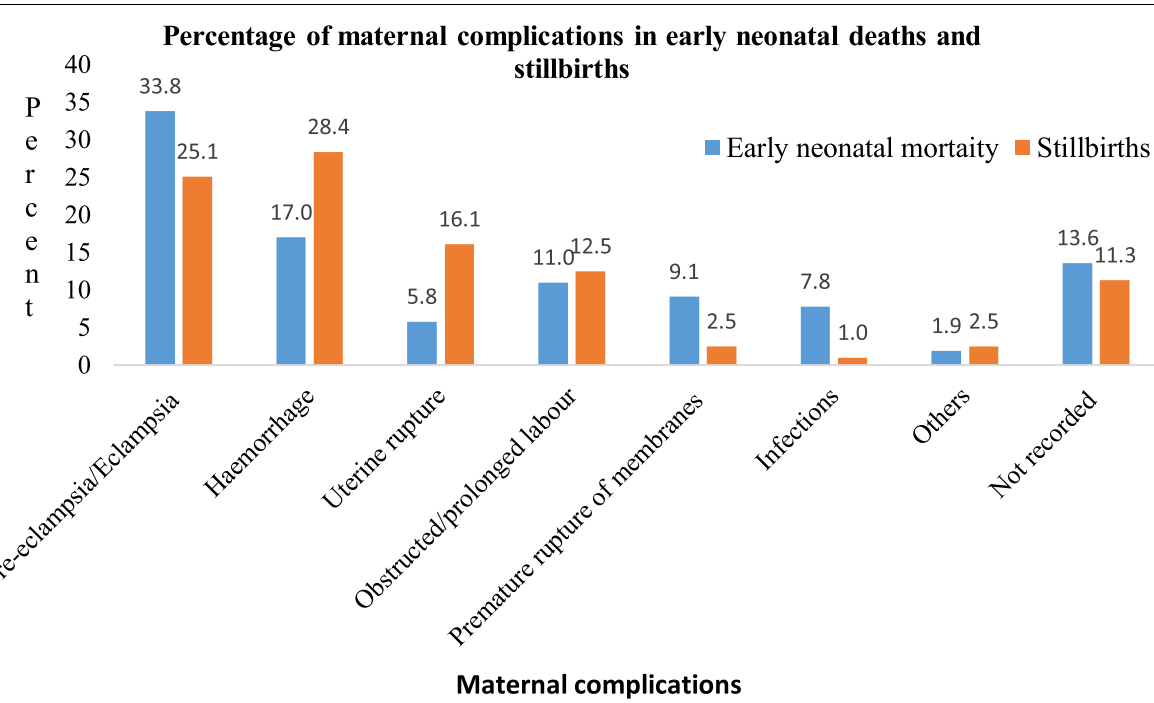

Fig. 6 The percentages of maternal complications in perinatal mortality in one specialized and one general hospital in south Ethiopia, 2014-2016

registers and newborn care is not addressed. A study undertaken in Ethiopia showed that the neonatal mortality rate was reduced by $1.9 \%$ annually [30]. The reason for the reduction in neonatal mortality can be explained by government commitments to increase (i) service availability to the mother and newborn and (ii) increasing the capacity of neonatal intensive care in Ethiopia. The reduction coincides with the deployment of a large number of health extension workers in the community to create awareness on the use of maternal health care services. Such improvements in outcomes related to policy changes can only be measured if accurate data are collected.

This study showed stillbirth rates of 55.2 per 1000 total births over the three-year study period. This prevalence was lower than other community and facility-based studies done in Ethiopia, at 71 and 85 per 1000 total births respectively [31, 32]. The reason for the difference can be explained by variation in the study period (the latter studies collected data from 2011 to 2013); every year there is an improvement in maternal health care service utilization and training of health care providers in Ethiopia. In 
Table 4 Determinants of early neonatal mortality in one specialized and one general hospital in south Ethiopia, 2014-2016

\begin{tabular}{|c|c|c|c|c|}
\hline \multirow[t]{2}{*}{ Variables } & \multicolumn{4}{|c|}{ Early neonatal deaths } \\
\hline & $\operatorname{Died}(n=318)$ & Survived $(n=11,778)$ & Crude OR $(95 \% \mathrm{Cl})$ & Adjusted OR $(95 \% \mathrm{Cl})$ \\
\hline \multicolumn{5}{|l|}{ Age category } \\
\hline$<=20$ & $45(14.1)$ & $1946(16.5)$ & 1 & \\
\hline $21-25$ & $106(33.3)$ & $4495(38.1)$ & $1.02(0.72-1.45)$ & $1.25(0.84-1.86)$ \\
\hline $26-30$ & $108(34.0)$ & $3929(33.4)$ & $1.19(0.84-1.69)$ & $1.27(0.85-1.89)$ \\
\hline $31-35$ & $47(14.8)$ & $1112(9.4)$ & $1.82(1.21-2.76)$ & $1.78(0.98-2.60)$ \\
\hline$>35$ & $12(3.8)$ & $296(2.5)$ & $1.75(0.92-3.35)$ & $1.32(0.63-2.78)$ \\
\hline \multicolumn{5}{|l|}{ Mode of delivery } \\
\hline Vaginal delivery & $255(80.2)$ & $4170(35.4)$ & $2.22(1.67-2.93)$ & $3.08(2.23-4.25)$ \\
\hline Caesarean section & $63(19.8)$ & $7608(64.6)$ & 1 & 1 \\
\hline \multicolumn{5}{|l|}{ Maternal status } \\
\hline Died/unstable or deteriorated & $44(13.8)$ & $52(0.44)$ & $36.21(23.81-55.05)$ & $7.54(4.14-13.71)$ \\
\hline Stable & $274(86.2)$ & $11,726(99.5)$ & 1 & 1 \\
\hline \multicolumn{5}{|l|}{ Maternal complication } \\
\hline Yes & $155(48.7)$ & $1450(12.3)$ & $6.77(5.40-8.50)$ & $2.71(2.01-3.66)$ \\
\hline No & $163(51.3)$ & $10,328(87.7)$ & 1 & 1 \\
\hline \multicolumn{5}{|l|}{ Previous history of caesarean section } \\
\hline Yes & $2(0.6)$ & $391(3.3)$ & $0.18(0.04-0.74)$ & $0.35(0.07-1.65)$ \\
\hline No & $316(99.4)$ & $11,387(96.7)$ & 1 & 1 \\
\hline \multicolumn{5}{|l|}{ Sex } \\
\hline Female & $110(34.6)$ & $5474(46.5)$ & 1 & 1 \\
\hline Male & $208(65.4)$ & $6304(53.5)$ & $1.64(1.29-2.07)$ & $1.51(0.95-1.96)$ \\
\hline \multicolumn{5}{|l|}{ APGAR Score at fifth minutes } \\
\hline$<7$ & $165(51.9)$ & $715(6.1)$ & $16.68(13.22-21.05)$ & $4.40(3.28-5.91)$ \\
\hline$>=7$ & $153(48.1)$ & $11,063(93.9)$ & 1 & 1 \\
\hline \multicolumn{5}{|l|}{ Birth weight (gm) } \\
\hline$<2500$ & $202(63.5)$ & $1031(8.7)$ & $18.15(14.32-23.01)$ & $6.4(4.77-8.58)$ \\
\hline$>=2500$ & $116(36.5)$ & $10,747(91.3)$ & 1 & 1 \\
\hline
\end{tabular}

\# $\mathrm{n}$ does not include twin births

this study, the trend of stillbirth rates has increased over the three years. Stillbirth rates increased by $14.6 \%$, with the highest stillbirth rates in 2015; an increase of $20.8 \%$. A possible explanation for this is not clear, but it may be due to a high number of complicated pregnancy referrals from other facilities. Another reason may be the fact that in this study the highest maternal death was reported in 2015 as a multicounty survey on maternal and newborn health done in low- and middle-income countries revealed that the majority of stillbirths occur in mothers with medical or obstetric complications [2].

The association between maternal deaths and complications and perinatal deaths have been reported in multiple studies [33-35]. Our findings are consistent with other findings in Ethiopia which showed both maternal deaths and complications increase the risk of perinatal deaths [36-39]. Taken together, these studies suggest the need to improve maternal health during pregnancy and birth to prevent perinatal deaths.
Our study found that vaginal births increase the risk of perinatal deaths. A multicounty survey study investigating maternal and newborn health report a higher prevalence of vaginal births in pregnancies resulting in perinatal deaths [40]. A case-control study in Ethiopia found that perinatal deaths were less likely among mothers who delivered by caesarean section than vaginal births [41]. In contrast, a cross-sectional study of perinatal deaths in Southern Ethiopia revealed that vaginal delivery reduced the risk of perinatal deaths [40]. A possible explanation for the differences in findings may result from the differences in sample size, data collection methods and study period.

Our results showed that low APGAR scores at five minutes and low birth weight increased the likelihood of early neonatal deaths. This is consistent with previous research, which reports low APGAR scores and birth weight were significantly associated with increased risk of early neonatal deaths [37, 41-43]. Furthermore, 
Table 5 Determinants of stillbirths in one specialized and one general hospital in south Ethiopia, 2014-2016

\begin{tabular}{|c|c|c|c|c|}
\hline \multirow[t]{2}{*}{ Variables } & \multicolumn{4}{|l|}{ Stillbirths } \\
\hline & Fetal deaths $(n=752)$ & $\begin{array}{l}\text { Liveborn neonates } \\
(\mathrm{n}=12,096)\end{array}$ & Crude odds ratios & $\begin{array}{l}\text { Adjusted odds } \\
\text { ratio with } \\
95 \% \mathrm{Cl}\end{array}$ \\
\hline \multicolumn{5}{|l|}{ Age category } \\
\hline$<=20$ & $103(13.7)$ & $1991(16.5)$ & 1 & 1 \\
\hline $21-25$ & $241(32.1)$ & $4601(38.0)$ & $1.01(0.80-1.28)$ & $1.07(0.84-1.37)$ \\
\hline $26-30$ & $252(33.5)$ & 4037 (33.4) & $1.21(0.95-1.53)$ & $1.22(0.96-1.56)$ \\
\hline $31-35$ & $111(14.8)$ & $1159(9.6)$ & $1.85(1.40-2.44)$ & $1.65(0.98-2.21)$ \\
\hline$>35$ & $45(5.9)$ & $308(2.5)$ & $2.82(1.95-4.09)$ & $2.60(0.75-3.86)$ \\
\hline \multicolumn{5}{|l|}{ Mode of delivery } \\
\hline Vaginal delivery & $541(71.9)$ & $7863(65.0)$ & $1.38(1.17-1.62)$ & $2.47(2.06-2.96)$ \\
\hline Caesarean section & $211(28.1)$ & $4233(35.0)$ & 1 & 1 \\
\hline \multicolumn{5}{|l|}{ Maternal status } \\
\hline Died/unstable & $54(7.2)$ & $96(0.8)$ & $9.6(6.86-13.61)$ & $2.51(1.74-3.62)$ \\
\hline Stable & $698(92.8)$ & $12,000(99.2)$ & 1 & 1 \\
\hline \multicolumn{5}{|l|}{ Maternal complication } \\
\hline Yes & $398(52.9)$ & 1605 (13.3) & $7.34(6.30-8.56)$ & $8.59(7.26-10.17)$ \\
\hline No & $354(47.1)$ & $10,491(86.7)$ & 1 & 1 \\
\hline
\end{tabular}

\# $\mathrm{n}$ does not include twin births

a study of predictive factors of low APGAR score at five minutes among singleton births in northwest Ethiopia has shown that low birth weight is significantly associated with increased low APGAR scores at five minutes [44]. The study in northwest Ethiopia indicates the effect of low birth weight on APGAR scores which in turn may increase the risk of early neonatal deaths [44]. These findings underscore the need for improved neonatal care for newborns who have low APGAR scores and birth weight to reduce the risk of neonatal death.

\section{Limitation of the study}

This study has three limitations. Firstly, the collected data were secondary, therefore it was difficult to collect all required information to assess predictors and causes of perinatal deaths. Secondly, the study was conducted in two hospitals only, thus the findings may not reflect the situations at all health facilities in the country. Thirdly, data were collected from the hospital delivery ward register and therefore, newborn deaths occurring after discharge may have been missed.

\section{Conclusion}

Though the magnitude of perinatal deaths declined by $21.6 \%$ over the three years, there is a wide range of problems with data collected in delivery ward registers. This study has shown a deficiency in data records, with the cause of death frequently not documented accurately or not recorded in delivery registers. Our findings show there is an opportunity to identify perinatal death and newborn outcomes from the delivery registers, but some important neonatal outcomes were not recorded. Appropriate documentation of the delivery register could have a major health implication, not only for newborn and maternal outcomes but also for program planning and evaluation. Training of health care providers is warranted to create and increase awareness of the importance of delivery registries and medical records to identify causes of the perinatal deaths occurring in health facilities. Policymakers and stakeholders should revise medical record forms and develop clear guidelines consisting of important variables related to perinatal outcomes. Moreover, continuous supervision and assessment of delivery ward registers is necessary. There is also a need to improve maternal health during pregnancy and birth, especially neonatal care for those neonates who experienced low APGAR scores and birth weight to reduce the prevalence of perinatal deaths.

\section{Future research}

Qualitative research is needed to increase understanding surrounding the possible reasons for incomplete records from the health care provider's perspective. Furthermore, research nationwide, including lower level and higher-level health facilities is necessary. 


\section{Implications of the study}

This study showed that determining the cause of perinatal deaths using delivery ward registers was possible, but there are gaps in record-keeping resulting in incomplete or unreliable data. Accurate recording and reporting of reliable data including number and cause of death within hospitals are important for program planning and monitoring. The use of a delivery ward register is one method to enhance awareness of why newborns die by revealing what type of treatment was given or not given to the newborn and also provides the leading cause of death. This provides information to policymakers on what actions need to be taken to reduce preventable perinatal deaths. Furthermore, understanding treatment provision in relation to mortality helps to identify unmet clinical needs in the hospital. Thus, health managers and policymakers in the country should work on improving documentation systems.

\section{Supplementary Information}

The online version contains supplementary material available at https://doi. org/10.1186/s12887-021-03058-4.

\section{Additional file 1.}

\section{Acknowledgements}

We would like to acknowledge the University of Newcastle, Australia, for funding TB's higher degree research and financing the research undertaking. We also want to thank the administrators of the hospitals and all staff working in the maternity unit who helped during the data collection period.

\section{Authors' contributions}

TB, CC, RS, and DL conceived the study. TB performed analysis. TB wrote the original draft of the manuscript. CC, RS, and DL revised the manuscript. All authors contributed to the writing and reviewed and approved the manuscript.

\section{Funding}

The University of Newcastle, Australia has funded the research as part of the research training program for $\mathrm{PhD}$ students (TB). The funder has no role in the design of the study, data collection, data processing and analysis and interpretation of the results of the study.

\section{Availability of data and materials}

The datasets used and/ or analysed during the current study are available from the corresponding author on reasonable request.

\section{Declarations}

\section{Ethics approval and consent to participate}

Ethical approval was obtained from the Human Research Ethics Committee (HREC) of the University of Newcastle, Australia (reference number: $\mathrm{H}$-20170253; date: 15 June 2018), and the Research Ethics Committee (IHREC) of the south Nation Nationalities People's Regional Health Bureau, Ethiopia (reference number: pm 37-186/24015). Organizational consent was obtained to access the delivery register from each of the hospitals. Since the data were collected from records patient consent was not required for this retrospective study, as the hospitals reserve the right to own the medical record of patients. All methods were carried out in accordance with relevant guidelines and regulations.
Consent for publication

Not applicable.

\section{Competing interests}

The authors declare that they have no competing interests.

\section{Author details}

${ }^{1}$ Priority Research Center for Healthy Lungs, Faculty of Health and Medicine, University of Newcastle, Callaghan, NSW, Australia. ${ }^{2}$ Hunter Medical Research Institute, Lot 1 Kookaburra Circuit, New Lambton Heights, NSW 2305, Australia. ${ }^{3}$ Centre for Women's Health Research, Faculty of Health and Medicine, University of Newcastle, Callaghan, NSW, Australia. ${ }^{4}$ The Mothers and Babies Research Centre at the Hunter Medical Research Institute, University of Newcastle, Callaghan, NSW, Australia.

Received: 25 September 2021 Accepted: 6 December 2021

Published online: 03 January 2022

\section{References}

1. Liu L, Oza S, Hogan D, Perin J, Rudan I, Lawn JE, et al. Global, regional, and national causes of child mortality in 2000-13, with projections to inform post-2015 priorities: an updated systematic analysis. Lancet (London, England). 2015;385(9966):430-40.

2. Vogel JP, Souza JP, Mori R, Morisaki N, Lumbiganon P, Laopaiboon M, et al. Maternal complications and perinatal mortality: findings of the World Health Organization Multicountry Survey on Maternal and Newborn Health. BJOG : an international journal of obstetrics and gynaecology. 2014;121(Suppl 1):76-88.

3. de Bernis L, Kinney MV, Stones W, Ten Hoope-Bender P, Vivio D, Leisher SH, et al. Stillbirths: ending preventable deaths by 2030. Lancet (London, England). 2016;387(10019):703-16.

4. World Health Organization. Neonatal and Perinatal Mortality: Country, Regional and Global Estimates 2006.

5. Richardus JH, Graafmans WC, Verloove-Vanhorick SP, Mackenbach JP. The perinatal mortality rate as an indicator of quality of care in international comparisons. Med Care. 1998;36(1):54-66.

6. WHO. International Classification of Diseases and Related Health Problems,10th Revision 1993;2.

7. Lawn JE, Blencowe H, Waiswa P, Amouzou A, Mathers C, Hogan D, et al. Stillbirths: rates, risk factors, and acceleration towards 2030. Lancet (London, England). 2016;387(10018):587-603.

8. UNICEF. Levels and trends in child mortality: estimates developed by the UN inter-agency group for child mortality estimation. 2015.

9. UN Inter-agency Group for Child Mortality Estimation. Levels and trends in child mortality: Report 2017. New York: UNICEF; 2017.

10. Lawn JE, Lee AC, Kinney M, Sibley L, Carlo WA, Paul VK, et al. Two million intrapartum-related stillbirths and neonatal deaths: where, why, and what can be done? International journal of gynaecology and obstetrics: the official organ of the International Federation of Gynaecology and Obstetrics. 2009;107 Suppl 1:S5-18, s9.

11. Lawn JE, Blencowe H, Pattinson R, Cousens S, Kumar R, Ibiebele I, et al. Stillbirths: Where? When? Why? How to make the data count? Lancet (London, England). 2011;377(9775):1448-63.

12. Vogel JP, Lee AC, Souza JP. Maternal morbidity and preterm birth in 22 low- and middle-income countries: a secondary analysis of the $\mathrm{WHO}$ Global Survey dataset. BMC pregnancy and childbirth. 2014;14:56.

13. UNICEF. Every child alive; The urgent need to end newborn deaths. Genève, Switzerland. 2018.

14. WHO. Making Every Baby Count Audit and review of stillbirths and neonatal deaths. 2016.

15. McClure EM, Saleem S, Pasha O, Goldenberg RL. Stillbirth in developing countries: a review of causes, risk factors and prevention strategies. J Matern Fetal Neonatal Med. 2009;22(3):183-90.

16. WHO. Monitoring Emergency Obstetric Care. Geneva. 2009

17. UN Inter-agency Group for Child Mortality Estimation. Levels and trends in child mortality: Report 2015. New York: UNICEF; 2015.

18. Ethiopian Public Health Institute (EPHI) [Ethiopia] and ICF. Ethiopia Mini Demographic and Health Survey 2019: Key Indicators. Rockville, Maryland, USA: EPHI and ICF. 2019. 
19. Federal Ministry of Health. National Strategy for Newborn and Child Survival in Ethiopia, 2015/16-2029/20. Addis Ababa, Ethiopia June 2015

20. Jena BH, Biks GA, Gelaye KA, Gete YK. Magnitude and trend of perinatal mortality and its relationship with inter-pregnancy interval in Ethiopia: a systematic review and meta-analysis. BMC Pregnancy and Childbirth. 2020;20(1):432.

21. Central Statistical Agency (CSA) [Ethiopia] and ICF International. The 2007 population and housing census of Ethiopia. Addis Ababa, Ethiopia. 2008.

22. Regional Health Bureau. Annual performance review meeting of 2006 EFY (2013/14). Hawassa, SNNPR,Ethiopia. 2014.

23. Iriya N, Manji KP, Mbise RL. Verbal autopsy in establishing cause of perinatal death. East Afr Med J. 2002;79(2):82-4.

24. Hazard RH, Chowdhury HR, Adair T, Ansar A, Quaiyum Rahman AM, Alam $S$, et al. The quality of medical death certification of cause of death in hospitals in rural Bangladesh: impact of introducing the International Form of Medical Certificate of Cause of Death. BMC Health Serv Res. 2017;17(1):688.

25. Pattinson R, Kerber K, Waiswa P, Day LT, Mussell F, Asiruddin SK, et al. Perinatal mortality audit: counting, accountability, and overcoming challenges in scaling up in low- and middle-income countries. International journal of gynaecology and obstetrics: the official organ of the International Federation of Gynaecology and Obstetrics. 2009;107 Suppl 1:S113-21, s21-2

26. Mbwele B, Reddy E, Reyburn H. A rapid assessment of the quality of neonatal healthcare in Kilimanjaro region, northeast Tanzania. BMC Pediatr. 2012;12:182.

27. Fitzgerald E, Mlotha-Mitole R, Ciccone EJ, Tilly AE, Montijo JM, Lang HJ, et al. A pediatric death audit in a large referral hospital in Malawi. BMC Pediatr. 2018;18(1):75.

28. Allanson ER, Muller M, Pattinson RC. Causes of perinatal mortality and associated maternal complications in a South African province: challenges in predicting poor outcomes. BMC pregnancy and childbirth. 2015;15:37.

29. Central Statistical Agency (CSA) [Ethiopia] and ICF International. Ethiopia Demographic and Health Survey 2016: Key Indicators Report. Addis Ababa, Ethiopia, and Rockville, Maryland, USA CSA and ICF. 2016.

30. Mekonnen Y, Tensou B, Telake DS, Degefie T, Bekele A. Neonatal mortality in Ethiopia: trends and determinants. BMC Public Health. 2013:13:483.

31. Adane AA, Ayele TA, Ararsa LG, Bitew BD, Zeleke BM. Adverse birth outcomes among deliveries at Gondar University Hospital, Northwest Ethiopia. BMC pregnancy and childbirth. 2014;14:90.

32. Lakew D, Tesfaye $\mathrm{D}$, Mekonnen $\mathrm{H}$. Determinants of stillbirth among women deliveries at Amhara region, Ethiopia. BMC pregnancy and childbirth. 2017;17(1):375.

33. Mmbaga BT, Lie RT, Olomi R, Mahande MJ, Olola O, Daltveit AK. Causes of perinatal death at a tertiary care hospital in Northern Tanzania 2000-2010: a registry based study. BMC Pregnancy Childbirth. 2012;12:139.

34. Vogel J, Souza J, Mori R, Morisaki N, Lumbiganon P, Laopaiboon M, et al. Maternal complications and perinatal mortality: findings of the World Health Organization Multicountry Survey on Maternal and Newborn Health. BJOG Int J Obstet Gynaecol. 2014;121(s1):76-88.

35. Khanam R, Ahmed S, Creanga AA, Begum N, Koffi AK, Mahmud A, et al. Antepartum complications and perinatal mortality in rural Bangladesh. BMC Pregnancy and Childbirth. 2017;17(1):81.

36. Debelew GT, Afework MF, Yalew AW. Determinants and causes of neonatal mortality in Jimma Zone, Southwest Ethiopia: a multilevel analysis of prospective follow up study. PLoS One 2014;9(9):e107184-e.

37. Goba GK, Tsegay H, Gebregergs GB, Mitiku M, Kim KA, Alemayehu M. A facility-based study of factors associated with perinatal mortality in Tigray, northern Ethiopia. Int J Gynaecol Obstet. 2018;141(1):113-9.

38. Liyew EF, Yalew AW, Afework MF, Essén B. Maternal near-miss and the risk of adverse perinatal outcomes: a prospective cohort study in selected public hospitals of Addis Ababa, Ethiopia. BMC pregnancy and childbirth. 2018;18(1):345-

39. Seyoum E, Bekele A, Tsegaye AT, Birhanu S. Magnitude and Determinants of Adverse Perinatal Outcomes in Tefera Hailu Memorial Hospital, Sekota Town, Northern Ethiopia. Global Pediatric Health. 2021:8:2333794X211015524.

40. Dessu S, Dawit Z. Perinatal Mortality and Associated Factors Among Antenatal Care Attended Pregnant Mothers at Public Hospitals in Gamo Zone, Southern Ethiopia. Frontiers in Pediatrics. 2020;8(869).
41. Getiye Y, Fantahun M. Factors associated with perinatal mortality among public health deliveries in Addis Ababa, Ethiopia, an unmatched case control study. BMC Pregnancy Childbirth. 2017;17(1):245.

42. Andegiorgish AK, Andemariam M, Temesghen S, Ogbai L, Ogbe Z, Zeng L. Neonatal mortality and associated factors in the specialized neonatal care unit Asmara, Eritrea. BMC Public Health. 2020;20(1):10.

43. Yego F, D'Este C, Byles J, Nyongesa P, Williams JS. A case-control study of risk factors for fetal and early neonatal deaths in a tertiary hospital in Kenya. BMC Pregnancy and Childbirth. 2014;14(1):389.

44. Zewude SB, Ajebe TM, Gessesse SS, Wassie TH. Proportion and predictive factors of low apgar score at five minute among singleton term neonates delivered in Debre Tabor specialized hospital, northwest Ethiopia: A cross-sectional study. International Journal of Africa Nursing Sciences. 2021:15:100322.

\section{Publisher's Note}

Springer Nature remains neutral with regard to jurisdictional claims in published maps and institutional affiliations.
Ready to submit your research? Choose BMC and benefit from:

- fast, convenient online submission

- thorough peer review by experienced researchers in your field

- rapid publication on acceptance

- support for research data, including large and complex data types

- gold Open Access which fosters wider collaboration and increased citations

- maximum visibility for your research: over $100 \mathrm{M}$ website views per year

At BMC, research is always in progress.

Learn more biomedcentral.com/submissions 